\title{
A Clinical Research on the Impact of Dexamethasone Versus Dexamethasone- Metoclopramide Combination in Reducing Postoperative Vomiting and Nausea After Cranial Surgery
}

Fahri Eryilmaz ${ }^{1}$, Umar Farooque ${ }^{2}$

1. Neurological Surgery, Hittite University Corum Erol Olcok Training and Research Hospital, Corum, TUR 2. Neurology, Dow University of Health Sciences, Karachi, PAK

Corresponding author: Umar Farooque, umarfarooque65@gmail.com

\section{Abstract}

\section{Introduction}

This brief study shows the consumption of two medications that are related to those patients who have gone through the complicated procedure of craniotomy. The basic aim of these drugs is to subside the aftereffects of the procedure like postoperative nausea and vomiting in patients. Hereby, the study outlines the functional efficiency of dexamethasone along with the metoclopramide and dexamethasone alone.

\section{Materials and methods}

Randomly two groups were listed of 120 patients that have undergone elective craniotomy with ASA I-II. These groups were called out as group A and group B. Group A was under the medication of combination of dexamethasone and metoclopramide $8 \mathrm{mg}$ and $10 \mathrm{mg}$, respectively, induced separately while group B was induced with $8 \mathrm{mg}$ of dexamethasone along with $2 \mathrm{ml}$ of normal saline. These drugs were induced right before anesthesia. The procedure from here on gets the same for both groups. After the surgical approach, a verbal evaluation was taken from the members of each group to collect specific data accordingly within the first 24 hours. As the method is double-blinded thus the patients were unaware of the ongoing research study. In any case of a mishap, rescue antiemetic drugs were also considered for the patients who would have experienced uncontrolled nausea and vomiting in the timeframe.

\section{Results}

The results show that only $16.7 \%$ of the patients from group A showed signs of nausea and only $5 \%$ showed vomiting while $31.7 \%$ of the patients from group B showed signs of nausea and $11.7 \%$ showed vomiting. It clearly showed that the patients tend to have either no sign of nausea and vomiting or showed little controllable nausea and vomiting when induced with dexamethasone and metoclopramide compared to those who were induced with the dexamethasone alone.

Review began 05/11/2021 Review ended 05/14/2021 Published 05/20/2021

(c) Copyright 2021 Eryilmaz et al. This is an open access article distributed under the terms of the Creative Commons Attribution License CC-BY 4.0., which permits unrestricted use, distribution, and reproduction in any medium, provided the original author and source are credited.

\section{Conclusions}

Postoperative nausea and vomiting are studied in terms of those who had undergone craniotomy. This study shows the prophylaxis of adverse effects of postoperative nausea and vomiting between the two groups under the influence of altered drugs. Thus, the results were noticeably in the favor of the combination treatment of dexamethasone and metoclopramide.

Categories: Neurology, Neurosurgery

Keywords: metoclopramide, dexamethasone, cranial surgery, nausea, neurosurgery, vomiting

\section{Introduction}

A craniotomy is a complicated procedure related to the neural function that can result in postoperative nausea and vomiting, moreover, this has been continued to be a cause of morbidity with adverse effects [1]. With the discoveries of the new antiemetic drugs, and modified anesthetic techniques followed by minimal invasiveness to surgical sites, the morbidity rate has been noticeably decreased [2]. Postoperative nausea and vomiting thus are the most commonly occurring after-effects of any surgical procedure and targets about $50 \%$ of the patients who have undergone craniotomy $[3,4]$. These adverse effects threaten life by dangerously elevating the arterial pressure and intracranial pressure of the patients [5]. All these contrary signs make the way for hemorrhage and ultimately for deaths. The minimal signs and symptoms associated with postoperative nausea and vomiting include dry mouth, sour taste, dehydration, electrolyte imbalance, restlessness, restricted mobilization, and fatigue giving more in-hospital phase to the patients and make a 
risk out of their health $[6,7]$. This study, discussed here, highlights all the necessary factors that tend to trigger postoperative nausea and vomiting after craniotomy and thus concludes the efficiency of the drug that helped to subside those adverse effects with less expenditure of time and health. So, in this scenario, the combination treatment tactic of dexamethasone and metoclopramide turned out to be more effective and useful.

\section{Materials And Methods}

This study was conducted at Dow University of Health Sciences, Karachi for a duration of one year from May 2019 to May 2020. It was approved by the Hospital Ethical Committee of Dow University of Health Sciences. It included 120 patients admitted to our hospital between the age of 33 and 65 years that were supposed to undergo craniotomy. This study is upon the method of a randomized clinical trial and was kept super confidential from the patients. All these patients were allocated into two groups A and B and were induced with drugs dexamethasone along with metoclopramide and dexamethasone alone, respectively. The standard dosage of $8 \mathrm{mg}$ of dexamethasone and $10 \mathrm{mg}$ of metoclopramide was given before anesthesia to group A, while group B only received $8 \mathrm{mg}$ of dexamethasone. All the essentials were kept under strict monitoring before inducing anesthesia with $2 \mathrm{mg} / \mathrm{kg}$ of propofol and $0.1 \mathrm{mg} / \mathrm{kg}$ of nalbuphine. The surgical procedure then proceeded with a similar protocol for all. A muscle relaxant was given followed by three minutes of monitoring; later, an endotracheal tube was intubated. Ventilation was monitored and surgery was completed. At the end of the surgery, volatile agent and nitrous oxide were turned off; $30 \mathrm{mg}$ of ketorolac was given for postoperative pain control, and $2.5 \mathrm{mg}$ of neostigmine with $0.5 \mathrm{mg}$ of glycopyrrolate was given for reversal of neuromuscular block, and the trachea was extubated on regaining spontaneous breathing and opening of the eyes. The smooth procedure of surgery was then followed by the strict evaluation for the first 24 hours and assessing any arising signs of postoperative nausea and vomiting by simple verbal cues from patients. Rescue antiemetic drug was given to the patients who experienced any nausea or unstoppable vomiting. It was easy to conduct the data of the patients as the majority from group A showed expected results of zero postoperative nausea and vomiting. However, the study is settled with the statistical data approach of the patients from both the group as qualitative variables of percentage. Other findings like age, weight, duration of surgery, surgical technique, and duration of anesthesia were analyzed by using student t-test, while gender, frequency, and intensity of nausea and vomiting and use of rescue antiemetic drugs were analyzed by using chi-square test. A p-value of less than 0.05 was considered significant.

\section{Results}

The results were taken free from any sort of bias concerning age, gender, weight, and physical status among the patients of the groups. The demographic features of the patients of both groups are shown in Table 1.

\begin{tabular}{|c|c|c|c|}
\hline Variable & Group A & Group B & p-value \\
\hline Age (years) & $47 \pm 18$ & $40 \pm 19$ & 0.928 \\
\hline Sex (male:female) & 33:27 & $31: 29$ & 0.851 \\
\hline Weight (kg) & $57 \pm 19$ & $52 \pm 17$ & 0.605 \\
\hline Duration of surgery (minutes) & $4 \pm 1.2$ & $4 \pm 1.4$ & 0.868 \\
\hline Duration of anesthesia (minutes) & $17 \pm 5$ & $17 \pm 6$ & 0.462 \\
\hline
\end{tabular}

TABLE 1: The demographic features of the patients.

kg: kilogram.

A rough statistical data was designed to put forward the aim and use of the drugs. Among the members of group A, about $83.3 \%$ of the patients showed absolutely no sign of nausea, while $16.7 \%$ had nausea and only about $5 \%$ showed vomiting within the first observatory 24 hours. Similarly, when looking at the data of group B, about $68.3 \%$ of patients showed no sign of nausea and vomiting whereas about $31.7 \%$ of the patients had nausea, and an estimated $11.7 \%$ showed vomiting in the specified timeframe as shown in Table 2. 


\section{Cureus}

\begin{tabular}{|c|c|c|c|c|}
\hline Time (hours) & Event & Group A & Group B & p-value \\
\hline \multirow[t]{2}{*}{ 0-2 } & Nausea & $7(11.7 \%)$ & $13(21.7 \%)$ & \\
\hline & Vomiting & $3(5 \%)$ & $5(8.3 \%)$ & \\
\hline \multirow[t]{2}{*}{$2-4$} & Nausea & $5(8.3 \%)$ & $6(10 \%)$ & \\
\hline & Vomiting & 0 & $4(6.7 \%)$ & \\
\hline \multirow[t]{2}{*}{ 4-24 } & Nausea & 0 & $4(6.7 \%)$ & \\
\hline & Vomiting & 0 & 0 & \\
\hline \multirow[t]{2}{*}{ First 24} & Nausea & $10(16.7 \%)$ & $19(31.7 \%)$ & 0.042 \\
\hline & Vomiting & $3(5 \%)$ & $7(11.7 \%)$ & 0.038 \\
\hline
\end{tabular}

TABLE 2: Incidence of postoperative nausea and vomiting.

This undoubtedly concluded that the frequency of nausea and vomiting observed is lower in those who were under the combination treatment management than those who took dexamethasone alone. Emergency conditions where $4 \mathrm{mg}$ of intravenous ondansetron was given to only three patients of group A while only about 11 patients needed it from group B as shown in Table 3 . This elevates the use of rescue antiemetics for those who opt for the drugs given to the patients of group B.

\begin{tabular}{|c|c|c|c|}
\hline Group & No of patients & Percentage & p-value \\
\hline A & 3 & $5 \%$ & \multirow{2}{*}{0.015} \\
\hline B & 11 & $18 \%$ & \\
\hline
\end{tabular}

TABLE 3: Use of rescue antiemetic drugs.

\section{Discussion}

This clinical-based research carried on the age group of 33-65 years of patients undergoing craniotomy has shown a great impact on the use of appropriate drugs for subsiding the rising postoperative issues like nausea and vomiting. The comparable study highlights the efficiency of dexamethasone when given in combination with metoclopramide or alone. As dexamethasone has been effective against vomiting and nausea thus it is called an antiemetic drug [8]. However, earlier dexamethasone was taken by patients after chemotherapy to reduce the chances of motion sickness, vomiting, and nausea. A new study gained attention when steroids were used for these adverse effects [9]. Steroids tend to become a threat to immunity and due to their high-intensity dose, it was reconsidered when using as an antiemetic drug [10,11]. The incidence and frequency of postoperative nausea and vomiting desirably reduced when dexamethasone replaced it. It became a helpful asset to the medical world and gained attention. Glucocorticoids were also used for a similar purpose but gets in vain when other harmful effects started to raise [12,13]. Moreover, metoclopramide being a D2 receptor acting as a central dopaminergic antagonist increases gastric emptying. Looking into the mechanisms of action of the different drugs used for the same purpose, it is seen that for the treatment of postoperative nausea and vomiting, dexamethasone was found to be superior in the control of nausea and vomiting [5]. However, the results of the statistical calculation obtained from the study weightage the theories about the efficiency of dexamethasone against vomiting and nausea [14-16].

\section{Conclusions}

The present clinical-based study demonstrated the statistical results of the combination treatment of drugs that include dexamethasone in addition to metoclopramide is superior to when dexamethasone is given alone in preventing postoperative nausea and vomiting in patients undergoing elective craniotomy, simplifying the complexity of neurosurgical health care facilities and adding more to life. Further studies on a larger scale are needed in the future to validate the results of this study.

\section{Additional Information}

\section{Disclosures}


Human subjects: Consent was obtained or waived by all participants in this study. Dow University of Health Sciences issued approval IRB-1805/DUHS/Approval/2019/3478. Animal subjects: All authors have confirmed that this study did not involve animal subjects or tissue. Conflicts of interest: In compliance with the ICMJE uniform disclosure form, all authors declare the following: Payment/services info: All authors have declared that no financial support was received from any organization for the submitted work. Financial relationships: All authors have declared that they have no financial relationships at present or within the previous three years with any organizations that might have an interest in the submitted work. Other relationships: All authors have declared that there are no other relationships or activities that could appear to have influenced the submitted work.

\section{References}

1. Xu G, Zhao J, Liu Z, Liu G, Liu L, Ren C, Liu Y: Dexmedetomidine combined with butorphanol or sufentanil for the prevention of post-operative nausea and vomiting in patients undergoing microvascular decompression: a randomized controlled trial. Front Med. 2020, 7:583031. 10.3389/fmed.2020.583031

2. Ashoor T, Kassim DY, Hasseb AM, Esmat IM: Effects of aprepitant/dexamethasone versus mirtazapine/dexamethasone on postoperative nausea and vomiting after laparoscopic sleeve gastrectomy: a randomized controlled trial. Research Square. 2020, 10.21203/rs.3.rs-107678/v1

3. Elvir-Lazo OL, White PF, Yumul R, Cruz Eng H: Management strategies for the treatment and prevention of postoperative/postdischarge nausea and vomiting: an updated review. F1000Res. 2020, 9:10.12688/f1000research.21832.1

4. Gan TJ, Belani KG, Bergese S, et al.: Fourth consensus guidelines for the management of postoperative nausea and vomiting. Anesth Analg. 2020, 131:411-48. 10.1213/ANE.0000000000004833

5. Murakami C, Kakuta N, Satomi S, et al.: Neurokinin-1 receptor antagonists for postoperative nausea and vomiting: a systematic review and meta-analysis. Rev Bras Anestesiol. 2020, 70:508-19. 10.1016/j.bjan.2020.04.005

6. Brijesh GC, Chekka NK, Kumar S, Prakash J, Sethi BK, Prabhu JP: A randomised controlled study evaluating the efficacy of dexamethasone in preventing post-operative nausea and vomiting and its effect on blood glucose. Indian Journal of Anesthesia and Analgesia. 2019, 6:2077-82. 10.21088/ijaa.2349.8471.6619.31

7. Zabirowicz ES, Gan TJ: Pharmacology of postoperative nausea and vomiting. Pharmacology and Physiology for Anesthesia. 2019 (ed): Elsevier, 2019. 2:671-92. 10.1016/B978-0-323-48110-6.00034-X

8. Hassan AM, Abdelzaam E: A comparative study between aprepitant only versus combined ondansetron and aprepitant as antiemetic therapy, regarding efficacy and duration. patients undergoing laparoscopic bariatric surgery double-blinded, randomized control clinical trial. J Anesth Clin Res. 2019, 10:2. 10.4172/2155-6148.1000893

9. Zhao C, Jia Y, Jia Z, Xiao X, Luo F: Pre-emptive scalp infiltration with ropivacaine plus methylprednisolone versus ropivacaine alone for relief of postoperative pain after craniotomy in children (RP/MP vs RP): a study protocol for a randomised controlled trial. BMJ Open. 2019, 9:e027864. 10.1136/bmjopen-2018-027864

10. Hussien N, El-Shmaas N: Hemodynamic effects of a single dose intravenous ketamine following cesarean section under spinal anesthesia: a randomized control trial. Arch Women Heal Gyn. 2019, 1-8. 10.39127/AWHG:1000118

11. Cata JP, Hagan K, Bravo M: Enhanced recovery after neurosurgical procedures (craniotomies and spine surgery). Textbook of Neuroanesthesia and Neurocritical Care. Prabhakar H, Ali Z (ed): Springer, Singapore; 2019. 1:493-501. 10.1007/978-981-13-3387-3_35

12. Santos CMT, Pereira CU, Chaves PHS, Tôrres PTRL, Oliveira DMDP, Rabelo NN: Options to manage postcraniotomy acute pain in neurosurgery: no protocol available. Br J Neurosurg. 2021, 35:84-91. 10.1080/02688697.2020.1817852

13. Moningi S, Patki A, Padhy N, Ramachandran G: Enhanced recovery after surgery: an anesthesiologist's perspective. J Anaesthesiol Clin Pharmacol. 2019, 35:S5-S13. 10.4103/joacp.JOACP_238_16

14. Hamed JME, Refaat HSM, Al-Wadaani H: Dexmedetomidine compared to remifentanil infusion as adjuvant to sevoflurane anesthesia during laparoscopic sleeve gastrectomy. Anesth Essays Res. 2019, 13:636-42. 10.4103/aer.AER_126_19

15. Matute GV, McHugh TM: Neurosurgery and post-surgical care of the critically ill cancer patients: craniotomy and stereotactic biopsy. Oncologic Critical Care. Nates J, Price K (ed): Springer, Cham; 2020. 1:1641-51. 10.1007/978-3-319-74588-6_150

16. Lalwani K: Emergence from anesthesia following pediatric neurosurgery. Essentials of Neurosurgical Anesthesia \& Critical Care. Brambrink A, Kirsch J (ed): Springer, Cham; 2020. 2:425-30. 10.1007/978-3-03017410-1_66 